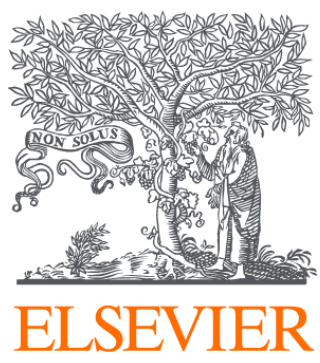

Since January 2020 Elsevier has created a COVID-19 resource centre with free information in English and Mandarin on the novel coronavirus COVID-

19. The COVID-19 resource centre is hosted on Elsevier Connect, the company's public news and information website.

Elsevier hereby grants permission to make all its COVID-19-related research that is available on the COVID-19 resource centre - including this research content - immediately available in PubMed Central and other publicly funded repositories, such as the WHO COVID database with rights for unrestricted research re-use and analyses in any form or by any means with acknowledgement of the original source. These permissions are granted for free by Elsevier for as long as the COVID-19 resource centre remains active. 
5. Peng PWH, Ho P-L, Hota SS. Outbreak of a new coronavirus: what anaesthetists should know. Br J Anaesth 2020; 124: 497-501
6. Marson BA, Anderson E, Wilkes AR, Hodzovic I. Bougierelated airway trauma: dangers of the hold-up sign. Anaesthesia 2014; 69: 219-23

doi: 10.1016/j.bja.2020.04.005

Advance Access Publication Date: 11 April 2020

(๑) 2020 British Journal of Anaesthesia. Published by Elsevier Ltd. All rights reserved.

\section{Fibreoptic tracheal intubation in COVID-19: not so fast}

\section{Craig Lyons}

Dublin, Ireland

E-mail: craigmacliathain@gmail.com

Keywords: airway management; apnoeic oxygenation; COVID-19; high-flow nasal oxygen; tracheal intubation

Editor-Wu and colleagues ${ }^{1}$ recently described the use of highflow nasal oxygen (HFNO) during fibreoptic tracheal intubation in critically ill patients with coronavirus disease 2019 (COVID19). This study was undertaken on the premise that fibreoptic tracheal intubation reduces the risk of virus transmission to the healthcare worker compared with laryngoscopy. The authors stated that they used fibreoptic bronchoscopy to 'reduce tracheal intubation-induced coughing and subsequent spread of virus'. However, the use of a neuromuscular blocking agent (used for all patients) eliminates coughing and increases the likelihood of intubation success with laryngoscopy. ${ }^{2}$ Furthermore, the authors stated that HFNO use is 'not associated with an increase in air or surface contamination' based on a recent study in critically ill patients with bacterial pneumonia. ${ }^{3}$ However, whilst this study demonstrated no greater risk of contamination with HFNO when compared with a control group using oxygen mask, contamination was indeed detected in both groups. In the study by $\mathrm{Wu}$ and colleagues, ${ }^{1}$ there was no use of an oxygen mask in the control arm during the apnoea period, whilst use of HFNO persisted in the intervention arm. Therefore, we cannot conclude, based on their evidence, that HFNO does not cause greater aerosolisation.

The degree of aerosolisation that is necessary to create a significant risk of COVID-19 infection to the clinician is perhaps the more relevant question, and this remains unknown. The fact that the six anaesthesiologists who undertook the study are 'currently not infected' is a positive observation, but is not an indicator of safety; this is a small number, and the rate of infection by any method of intubation is not known to be as high as 1:6 with adequate personal protective equipment.

The primary endpoint of 'intubation time' was defined as the period from the beginning of bronchoscopy until proper tracheal tube placement was confirmed. The intubation time was $7 \mathrm{~s}$ shorter in the HFNO arm vs face-mask arm. Whilst reaching statistical significance, this is arguably clinically insignificant. The higher minimum $\mathrm{Spo}_{2}$ of $94 \%$ vs $91 \%$ during tracheal intubation with HFNO us standard mask oxygenation is also clinically insignificant, particularly given that there was no difference between both groups in the incidence of $\mathrm{SpO}_{2}$ $<80 \%$ during intubation. The time period between the onset of apnoea and the verification of tracheal tube position is a more classical measure of the time it takes to intubate a patient, as this best represents the period where the patient is depleting their preoxygenation reserves. This period was $60 \mathrm{~s}$ longer than the 'intubation time' quoted, as the anaesthesiologists first waited $60 \mathrm{~s}$ to enable a dose of rocuronium $1 \mathrm{mg} \mathrm{kg}^{-1}$ to take effect. Based on the figures supplied, it took an estimated $2 \mathrm{~min}$ and $20 \mathrm{~s}$ from the onset of apnoea to intubate $75 \%$ of the patients. As tracheal intubation via laryngoscopy would likely not have taken this long, this represents an unnecessarily long duration of exposure. Furthermore, the authors expressed a desire to avoid bag-mask ventilation as it intensifies viral spread. However, in taking longer to secure the airway, the likelihood of oxygen desaturation was increased, which may then paradoxically require bag-mask ventilation. Bag-mask ventilation is more likely to be avoided by performing laryngoscopy in the first instance.

Whilst fibreoptic intubation may allow the anaesthetist to stand a greater distance away from the airway, optimal technique involves holding the controller vertically above the airway, limiting the distance achieved from the patient. Additionally, there is greater contact with the airway as the scope is typically stabilised with the hand over the nose or mouth-areas that can have a significant viral load. The authors do not state whether they performed nasal or oral fibreoptic intubations. This is of relevance when HFNO is being used as a nasal route of tube passage greatly limits oxygen insufflation through the nare used for the bronchoscope.

The merits of using HFNO during the preoxygenation phase of the study, as seen in this RCT, are questionable. A recent study has indicated that face-mask preoxygenation is superior to HFNO preoxygenation, likely because a tight-fitting face mask prevents entrainment of room air, and implies that any benefit from HFNO arises with apnoeic oxygenation alone. ${ }^{4}$ For anaesthetists attempting this technique, the benefits of both a face mask and HFNO can be harnessed by using a face mask 
alone for preoxygenation followed by HFNO insufflation during the apnoeic period. ${ }^{5,6}$

The authors concluded that HFNO 'provided a shorter intubation time and less frequent incidence of desaturation during attempts at fibreoptic tracheal intubation compared with preoxygenation by face-mask ventilation'. Irrespective of the superiority of one method over another, neither of these has been compared with the standard of care of rapid sequence intubation, and both may represent inferior alternatives.

\section{Declaration of interest}

The author declares that they have no conflicts of interest.

\section{References}

1. Wu CN, Xia LZ, Li KH, et al. High-flow nasal-oxygenationassisted fibreoptic tracheal intubation in critically ill patients with COVID-19 pneumonia: a prospective randomised controlled trial. $\mathrm{Br} J$ Anaesth 2020. https://doi.org/ 10.1016/j.bja.2020.02.020. Advance Access Published March 19

2. Lundstrøm LH, Duez CHV, Nørskov AK, et al. Effects of avoidance or use of neuromuscular blocking agents on outcomes in tracheal intubation: a Cochrane systematic review. Br J Anaesth 2018; 120: 1381-93

3. Leung CCH, Joynt GM, Gomersall CD, et al. Comparison of high-flow nasal cannula versus oxygen face mask for environmental bacterial contamination in critically ill pneumonia patients: a randomized controlled crossover trial. J Hosp Infect 2019; 101: 84-7

4. Shippam W, Preston R, Douglas J, Taylor J, Albert A, Chau A. High-flow nasal oxygen vs. standard flow-rate facemask pre-oxygenation in pregnant patients: a randomised physiological study. Anaesthesia 2019; 74: 450-6

5. Lyons C, Callaghan M. Uses and mechanisms of apnoeic oxygenation: a narrative review. Anaesthesia 2019; 74: 497-507

6. Renda T, Corrado A, Iskandar G, Pelaia G, Abdalla K, Navalesi P. High-flow nasal oxygen therapy in intensive care and anaesthesia. $\mathrm{Br} J$ Anaesth 2018; 120: 18-27

\title{
Rapid ramp-up of powered air-purifying respirator (PAPR) training for infection prevention and control during the COVID-19 pandemic
}

\section{Qingyan Chen", Beatrice Lim, Shimin Ong, Wan-Yi Wong and Yu-Chin Kong}

\author{
Singapore \\ *Corresponding author. E-mail: qingyan_chen@ttsh.com.sg
}

Keywords: airway management; anaesthesia; COVID-19; infection prevention and control; PAPR; tracheal intubation

Editor-Singapore's first coronavirus disease 2019 (COVID-19) patient was diagnosed on January 23,2020 . This triggered an urgent ramp-up of just-in-time (JIT) training to expedite development of infection prevention and control capabilities in the Department of Anaesthesiology, Intensive Care, and Pain Medicine of Tan Tock Seng Hospital in anticipation of a rapidly escalating COVID-19 pandemic.

Frequent involvement in aerosol-generating procedures (AGPs) such as tracheal intubation, extubation, and open airway procedures including tracheostomy and bronchoscopy $^{1}$ exposes our staff to high risk of contamination. Proper use of a hooded powered air-purifying respirator (PAPR) offers better protection against respiratory pathogens during AGPs, with an assigned protection factor (APF) of up to 1000 compared with an APF of 10 for a N95 respirator. ${ }^{2}$ Our hospital uses two types of PAPRs: the $3 \mathrm{M}^{\mathrm{TM}}$ Jupiter ${ }^{\mathrm{TM}}$ with $3 \mathrm{M}^{\mathrm{TM}} \mathrm{HT}-101$ Lightweight Hood (Fig 1) and the $3 \mathrm{M}^{\mathrm{TM}}$ Versaflo ${ }^{\mathrm{TM}} \mathrm{TR}-300$ with $3 \mathrm{M}^{\mathrm{TM}}$ Hood Assembly S-855. In the initial phase of our pandemic response plan, our department prioritised JIT resources for infection prevention and control measures against AGP, with a focus on PAPR training, as these are infrequently used, and their effectiveness requires a high level of staff involvement.

\section{Development of a PAPR training programme} Pre-requisites

All staff had been N95 mask-fitted and had undergone two PAPR training sessions with competency checks, one each for Jupiter $^{\mathrm{TM}}$ and Versaflo ${ }^{\mathrm{TM}}$ PAPRs. These covered the basic operation and donning and doffing of the PAPRs.

Timeline

Our department's infection prevention and control team was formed on January 28, 2020 and aimed to complete departmental PAPR training before Singapore progressed to a heightened risk. We allocated 2 weeks each for the training of Jupiter ${ }^{\mathrm{TM}}$ and Versaflo ${ }^{\mathrm{TM}}$ PAPR, and this allowed comprehensive one-on-one training for all 96 anaesthetists within February 2020. 